TABLE I Patients with various diagnoses

\begin{tabular}{ccclcccc}
\hline Patient & Sex & Age & \multicolumn{1}{c}{ Diagnosis } & FA & USG & RIS \\
\hline 1 & F & 88 & $\begin{array}{l}\text { Disciform macular degeneration with subretinal } \\
\text { haemorrhage }\end{array}$ & NA & - & - \\
2 & M & 24 & Haemangioma & \pm & - & - \\
3 & M & 66 & Naevus or melanoma & \pm & \pm & - \\
4 & F & 70 & Rectinal pigment epithelial hyperplasia & - & - & - \\
5 & M & 47 & Retinal pigment epithelial dystropy & - & - & -
\end{tabular}

$F A=$ fluorescein antiography. USG=ultrasonography. RIS=radioimmunoscintigraphy. NA=not available. $\downarrow=$ not available due to peripheral localisation.

possibility of a false positive result due to tracer uptake in a naevus should be kept in mind.

1 Tullo AB, Dodd CL, Noble JL, Owens S. Rao H. Ocular melanoma. Brf Ophthalmol 1989; 73: 771. Ocular melan 1989; 73: 772 .

Schaling DF, Van Kroonenburgh MJPG, Borsje

3 Schaling DF, Van Kroonenburgh MJPG, Borsje
RA, et al. Radioimmunoscintigraphy with melanoma associated monoclonal antibody fragments in ocular melanoma. Graefes Arch Clin Exp Ophthalmol 1989; 227: 291-4.

4 Bomanii J, Nimmon CC, Hungerford JL, Solanski $\mathrm{K}$, Granowska M, Britton KE. Ocular radioimmunoscintigraphy: sensitivity and practical considerations. F Nucl Med 1988; 29: 1038-44.

\section{- BOOK REVIEWS}

Proliferative Vitreoretinopathy (PVR). Eds H MacKenzie Freeman, Felipe I Tolentino. Pp 197. DM 148.00. Springer-Verlag: London. 1988.

In this book, the first devoted entirely to PVR, the editors have assembled 27 papers dealing with the pathology, the management, and current research into this difficult condition The material is presented under three main headings: an update, a discussion of common concerns, and reports of current clinical and research studies.

After an introductory overview of the general concepts of PVR there follows a number of clinical papers on the management of it in its increasing stages of complexity. These range from clinical and animal studies of the role of scleral buckling, and expansile gases without vitrectomy by Stanley Chang, to Zivojnovic's astounding collection of longstanding retinal detachments in severely traumatised eyes and their near miraculous recovery. The middle section is devoted to an almost verbatim transcript of a round table discussion by a number of well known experts in the vitreoretinal field. The last 17 articles range from a description of the organisation of the multicentre treatment trial which compares the use of silicone oil with that of expansile gases, to purely laboratory studies of drug delivery and the pharmacological manipulation of the cellular processes involved in the pathogenesis of PVR.

This book makes very interesting reading for those concerned in the management of patients with PVR. Being mostly a compilation of papers presented at the 1986 Academy Meeting, it suffers from a certain amount of repetition in the introductions and discussions in each paper. The 'current research studies' are by now over two years old, and much has happened since in the busy research on the intricacies of proliferative vitreoretinopathy.
D F SCHALING J A OOSTERHUIS Department of Ophthalmology, University Hospital, Rijnsburgerweg 10 2333 AA Leiden

The Netherlands

E K J PAUWELS Department of Diagnostic Radiology, Subdivision of Nuclear Medicine University Hospital Rijnsburgerweg 10 2333 AA Leiden The Netherlands Potentials and Evoked Magnetic Fields in Science and Medicine. By David Regan. Pp 672. US\$140·00. Elsevier: New York. 1989.

This is a single author textbook which is going to provide an important reference source for any electrodiagnostic clinic. Although the author writes from the point of view of the electronic engineer, his scope is wide. The book is in three sections. The first is divided into technical and mathematical considerations the second is on basic research, and the third is on clinical applications. The main emphasis of the book concerns basic research and research techniques, and, although the clinical section is fairly short, it has been well written. The book is concerned with all forms of evoked potential, including visual, auditory, and somatosensory. The author is a well known authority in the field, and in this work his original textbook has been greatly expanded and updated. It will be welcomed by anyone concerned with the electrophysiology of the brain.

N R GALLOWAY

Clinical Ophthalmology. 2nd Edn. By Jack J Kanski. Pp 491. £75. Butterworths: Guildford, Surrey. 1989.

There is no better testimony to a successful book than the appearance of a second edition within five years after its original publication. In Clinical Ophthalmology Jack Kanski demonstrates the art of the master textbook writer: the text is well laid out, brief yet comprehensive. It covers all the important ophthalmic conditions, with the salient features of their clinical histories, physical signs, and management Although the text is not referenced, there is an adequate list of suggested reading, which is as up to date as any newly published textbook can provide. The illustrations by Terry Tarrant are superb, and they admirably complement the wealth of colour photographs.

It is difficult to fault this excellent book. It has become the standard text for trainee ophthalmologists, both in Britain and elsewhere, and can also serve as a comprehensive reference book for practising ophthalmologists.

Z J GREGOR
Diabetes and Its Ocular Complications. By William E Benson, Gary C Brown, William Tasman. Pp 197. $£ 40 \cdot 50$. Saunders: London. 1988.

This is a beautifully produced book which covers most clinical aspects of diabetic retinopathy. It also has chapters on pathology, together with four chapters on diabetic tissue damage and coagulation changes. There is a useful chapter on differential diagnosis of diabetic retinopathy. The book could be particularly useful to residents wanting to learn about this common condition, which is a major cause of blindness in the developed world.

But there are also many shortcomings. Papers are cited and reviewed without any criticism, and all statements made by different authors quoted are taken at face value, without any indication of which studies are based on too few patients or inadequate statistical analysis. Nor do the authors come up with definite suggestions or conclusion at the end of the chapters; this is most noticeable in chapter 14, on medical treatment of diabetic retinopathy.

A further shortcoming is that, when discussing pathogenic mechanisms, the authors do not mention the tremendous amount of work done in the field of cell culture. The papers quoted are extensive, but there are almost none from 1987 and few from 1986. Thus, although a new book, it is in the nonclinical aspects already out of date. This is really an indication of the rapid expansion of work in the field of retinopathy and the slow production of books.

While the book is a useful addition for residents, I do not think that it is of value to the researcher in the field of diabetic retinopathy.

E M KOHNER

A Colour Atlas of Contact Lenses and Prosthetics. 2nd Edn. By Montague Ruben. Pp 199. £35. Wolfe Medical: London, 1989

This superb collection of illustrations covers a wide ranging though at times eclectic collection of topics on contact lenses. They demonstrate the author's breadth of expertise in many areas of contact lens practice, particularly in lens materials and design and in the fitting of the abnormal eye. The text is sometimes too concise to illuminate the understanding of the pedestrian reader, though the diagrams do much to overcome this. The book is an entertaining companion to more formal texts on contact lens practice.

JOHN DART

Brain and Reading. Eds. Curt von Euler, Ingvar Lundberg, Gunnar Lennerstrand. Pp 390. £50.00. Macmillan: Basingstoke, Hants. 1989.

The Rodin Remediation Conferences have acquired a reputation for excellent if occasionally eccentric meetings, in which a goodly collection of eminent speakers from a range of disciplines share the stage with a handful of more controversial and shadowy figures from the world of dyslexia research. In the early meetings there was a strong emphasis on visual factors, but this has progressively declined to the point where in these proceedings less than one-third of the papers are concerned with the visual system.

This is not a book for the novice. The papers do not follow a coherent theme, and the editorial contribution is largely confined to 